\title{
Geographical Distribution of Visceral Leishmaniasis Among Children in Dhamar Governorate, Yemen
}

\author{
Abdulhakim Ali Mohammed Al-Selwi, Ahmed Hamood Alshehari, Mohamed Abdulhadi Albahloly \\ Pediatric Department, Faculty of Medicine, Dhamar University, Dhamar, Yemen \\ Email address: \\ hakimselwi@gmail.com (A. A. M. Al-Selwi), shehari250@yahoo.com (A. H. Alshehari), moham14@live.com (M. A. Albahloly) \\ To cite this article: \\ Abdulhakim Ali Mohammed Al-Selwi, Ahmed Hamood Alshehari, Mohamed Abdulhadi Albahloly. Geographical Distribution of Visceral \\ Leishmaniasis Among Children in Dhamar Governorate, Yemen. Journal of Health and Environmental Research. \\ Vol. 4, No. 1, 2018, pp. 16-20. doi: 10.11648/j.jher.20180401.13
}

Received: July 7, 2017; Accepted: July 18, 2017; Published: March 6, 2018

\begin{abstract}
This is a retrospective study to describe the geographical distribution of visceral leishmaniasis among children in Dhamar governorate, Yemen and to assess the outcomes of the chemotherapeutic management. It was conducted at $\mathrm{Al} \mathrm{-}$ Wahdah University Hospital, Mabar, Dhamar governorate from April 2015 to March 2016. The study population were all the patients admitted to the hospital having the disease and the data sourced from the patients "charts using a performa sheet. Fiftyseven pediatric patients with confirmed visceral leishmaniasis were registered during the study period. The mean age was $3.51 \pm 2.4$ years and all cases were from Dhamar governorate. All cases presented with fever and splenomegaly. All children were severely anemic and the mean haemoglobin concentration was $(6.51 \pm 2.82 \mathrm{~g} / \mathrm{dl})$. The mean duration of symptoms prior to admission was $98.28 \pm 10.6$ days and the mean hospital stay was $22.07 \pm 15.3$ days. The cure rate after hospital management was 94.7\%. Death had occurred in 3 cases (5.2\%) mostly seen among younger age, and with prolonged illness prior to hospitalization. This study confirmed the presence of VL cases in Dhamar governorate, most frequently affected children below four years of age with excellent response to chemotherapeutic drug. The extension of visceral leishmaniasis infection to involve the highest central regions indicates that the disease tend to spread to other unusual parts of the country. Such a new distribution combined with lack of vital recording and reporting make the efforts to approximate the figure of true incidence difficult.
\end{abstract}

Keywords: Visceral Leishmaniasis, Paediatrics, Yemen

\section{Introduction}

Visceral leishmaniasis (VL) is the most severe form of leishmaniasis with high mortality if not treated. The disease is caused by protozoan parasites that belong to the genus Leishmania and is transmitted by the bite of certain species of sand fly [1]. It is estimated that over 200 million people around the world are at risk of acquiring the disease [2], and about 500000 new cases per year of VL globally are recorded [3]. VL is one of the seven most neglected tropical disease in the world [4]. The disease occurs in focal distribution and in remote locations, making extrapolation from official data sources difficult [5]. The prevalence of VL in pediatric population is high due to the higher susceptibility to infections and the immune-depressed state found in this population [6]. The majority of pediatric patients present with fever, anemia, hepatosplenomegaly, weight loss, haemorrhage, lymphadenopathy and less frequently dry cough and diarrhea [7].

The diagnosis of VL is usually suggested by clinical and laboratory findings but the definitive diagnosis is based on identification of the parasites in bone marrow, liver, spleen or lymph node tissues $[7,8]$. VL is considered endemic in our country and confined mainly to low- lying rural areas with high temperature [9]. Al-Selwi previous study on the topic [10] highlighted the extension of the VL foci towards some governorates which considered suburban regions. Recently, VL cases recorded among the central highlands that represent the highest area in the country. The aim of this study is to describe retrospectively the geographical distribution of visceral leishmaniasis among children in Dhamar governorate and to assess the outcomes of the chemotherapeutic management. 


\section{Patients and Methods}

\subsection{Study Design}

This is a retrospective hospital-based study conducted at the paediatric unit in Al- Wahdah University Hospital, Dhamar governorate, Yemen from April 2015 to March 2016.

\subsection{The Study Area}

Dhamar, is one of the high land governorates of Yemen. It is located $100 \mathrm{Km}$ to the south of Sana'a governorate. It is administratively divided into 12 districts covering a surface area of $8,745 \mathrm{~km}^{2}$ with a total population of $1,330,108$ (Census 2004) (11).

\subsection{Data Collection}

The pediatric clinical data were obtained by the retrospective analysis of the medical records. The ethical clearance for the study was obtained from the university ethical committee. We included all pediatric patients who aged between 0 to 12 years. All patients were diagnosed as having VL based on the identification of leishmania donovani bodies (LDB) in smears obtained by Bone Marrow Aspiration from the posterior iliac crest or upper tibia. The clinical findings at time of admission were recorded and the history details, physical examination were retrieved from the patient's charts. The investigations reviewed were complete blood count including hemoglobin concentration, total leukocytes with differential, platelet count, erythrocyte sedimentation rate (ESR), smear for malarial parasites and urinalysis. The onset of symptoms and the duration of illness prior to admission, treatment, length of hospital stay, complications during the treatment course and the outcome were noted. In this study, we defined anemia as $\mathrm{Hb}(<11 \mathrm{~g} / \mathrm{dl})$, and severe anemia as $(\mathrm{Hb}$ $<7 \mathrm{~g} / \mathrm{dl})$, neutropenia $(<1500 / \mu 1 \quad$ neutrophils $)$ and thrombocytopenia $(<150000 / \mu 1$ platelets $)$. Within the hospital, all pediatric patients received adjunctive treatment such as blood and blood products, symptomatic medication, and dietary support. Sodium stibogluconate was administered $(20 \mathrm{mg} / \mathrm{kg} /$ day $)$ intravenously for a total of 28 days. All cured pediatric patients were followed-up for 4 month after discharge.

\subsection{Statistical Analysis}

All statistical analyses were performed using SPPS version 21 (IBM, lnc, Chicago, 1L). Categorical data were summarized as frequencies and percentages of subjects, continuous data as mean, standard deviation and range. Chisquare tests and t-student tests were applied where needed. Statistical significance was defined as $\mathrm{P}$ value of $<0.05$.

\section{Results}

A total of 57 cases of pediatric confirmed VL were registered in Al Wahdah University Hospital during the study period. The mean age was $3.51 \pm 2.4$ years with almost $2 / 3^{\text {rd }} \leq 4$ years old. There were $(59.6 \%)$ males. Table 1 , summarizes the pediatric characteristic. All cases were from Dhamar governorate distributed amongst the highland settings in scattered villages. The majority of VL cases $(45.6 \%)$ were identified in Anes destrict, (24.5\%) from A'ns, (19.2\%) from Wesab, (5.2\%) from Al hada and (5.2\%) from Automah. Figure 1.

Table 1. The characteristics of the pediatric patients ( $n=57)$.

\begin{tabular}{lll}
\hline variable & Mean \pm SD or $\mathbf{n}(\%)$ & P value \\
\hline Age $(\mathrm{yr})$ & $3.51 \pm 2.4$ & \\
$\leq 1$ & $4(7)$ & $<0.00$ \\
$2-4$ & $38(66.6)$ & \\
$5-10$ & $17(29.8)$ & $<0.00$ \\
Sex & & \\
Male & $34(59.6)$ & 0.01 \\
Female & $23(40.3)$ & \\
Body weight $(\mathrm{kg})$ & $9.93 \pm 4.1$ & \\
Family occupation & & \\
Agriculture & $43(75.4)$ & $<0.00$ \\
Others & $14(24.6)$ & \\
\hline
\end{tabular}

Fever was presented in almost all cases likewise, splenomegaly found among all affected children. Pallor (86\%), abdominal distension (80.7\%), hepatomegaly (77.1\%), anorexia $(56.1 \%)$ and loss of weight $(40.3 \%)$ were the predominant clinical presentation (Table 2). The mean Hemoglobin concentration was $6.51 \pm 2.82 \mathrm{~g} / \mathrm{d}$ with $(61.4 \%)$ had $\mathrm{Hb} \leq 7 \mathrm{~g} / \mathrm{dl}$. Neutropenia was observed in 10 cases $(17.5 \%)$ and platelet count $<100 \times 10^{3} / \mu 1$ was observed in 29 cases $(50.8 \%)$. Table 3 shows the main haematological findings.

The mean duration of symptoms before admission was 98.28 \pm 10.6 days (range 2-370) and the mean hospital stay was $22.07 \pm 15.3$ days (range 7-46). The cure rate of medical management was $(94.7 \%)$ and the death rate was $(5.2 \%)$. The three cases who died were aged less than a year, and complicated by secondary infection, and hemorrhage (Table 4). There was no relapse recorded during the follow-up period.

Table 2. Clinical symptoms and signs of the affected children $(n=57)$.

\begin{tabular}{ll}
\hline Variable & no (\%) \\
\hline Fever & $57(100)$ \\
Splenomegaly & $57(100)$ \\
Pallor & $49(86)$ \\
Abdominal distension & $46(80.7)$ \\
Hepatomegaly & $44(77.1)$ \\
Anorexia & $32(56.1)$ \\
Loss of weight & $23(40.3)$ \\
Lower limb edema & $8(14)$ \\
Chest infection & $6(10.5)$ \\
Jaundice & $6(10.5)$ \\
Lymphadenopathy & $3(8.7)$ \\
\hline
\end{tabular}


Table 3. Hematological findings of the affected children $(n=57)$.

\begin{tabular}{llll}
\hline Variable & mean \pm SD & $\mathbf{9 5 \%}$ CI & P value \\
\hline $\mathrm{Hb}(\mathrm{g} / \mathrm{dl})$ & $35(61.4)$ & $3.2433-40.6211$ & 0.01 \\
$<7$ & $22(38.6)$ & & \\
$7-11$ & $6.51 \pm 2.82$ & & $<0.00$ \\
$\mathrm{Mean} \pm \mathrm{SD}$ & & $32.34-59.33$ & \\
$\mathrm{WBC}\left(\mathrm{mm}^{3}\right)$ & $26(45.6)$ & & $<0.00$ \\
$<4000$ & $4.28 \pm 3.87$ & $8.72-29.86$ & \\
Mean $\pm \mathrm{SD}$ & $10(17.5)$ & & $<0.001$ \\
Neutrophil $\left(\mathrm{mm}^{3}\right)$ & $2848 \pm 511$ & $37.22-64.30$ & \\
$<1500$ & $29(50.8)$ & & \\
Mean $\pm \mathrm{SD}$ & $102.1 \pm 6.045$ & & \\
Platelet $\left(1000 / \mathrm{mm}^{3}\right)$ & $58.42 \pm 18.1$ & & \\
$<100$ & & & \\
Mean $\pm \mathrm{SD}$ & & & \\
ESR & & & \\
\hline
\end{tabular}

he data presented as means $\pm \mathrm{SD}$ or $\mathrm{n}(\%)$ and range

Table 4. Duration of disease and outcomes.

\begin{tabular}{llll}
\hline Variable & mean \pm SD & 95\% CI & P value \\
\hline Duration of illness (day) & $98.28 \pm 10.6$ & $95.4674-101.0926$ & $<0.001$ \\
Range & $(2-370)$ & & $<0.001$ \\
Hospital stay (day) & $22.07 \pm 15.3$ & $18.0104-26.1296$ & \\
Range & $(7-46)$ & $85.33-98.88$ & $<0.001$ \\
Cured & $54(94.7)$ & & \\
Death & $3(5.2)$ & & \\
\hline
\end{tabular}

The data presented as means \pm SD or $\mathrm{n}(\%)$ and range

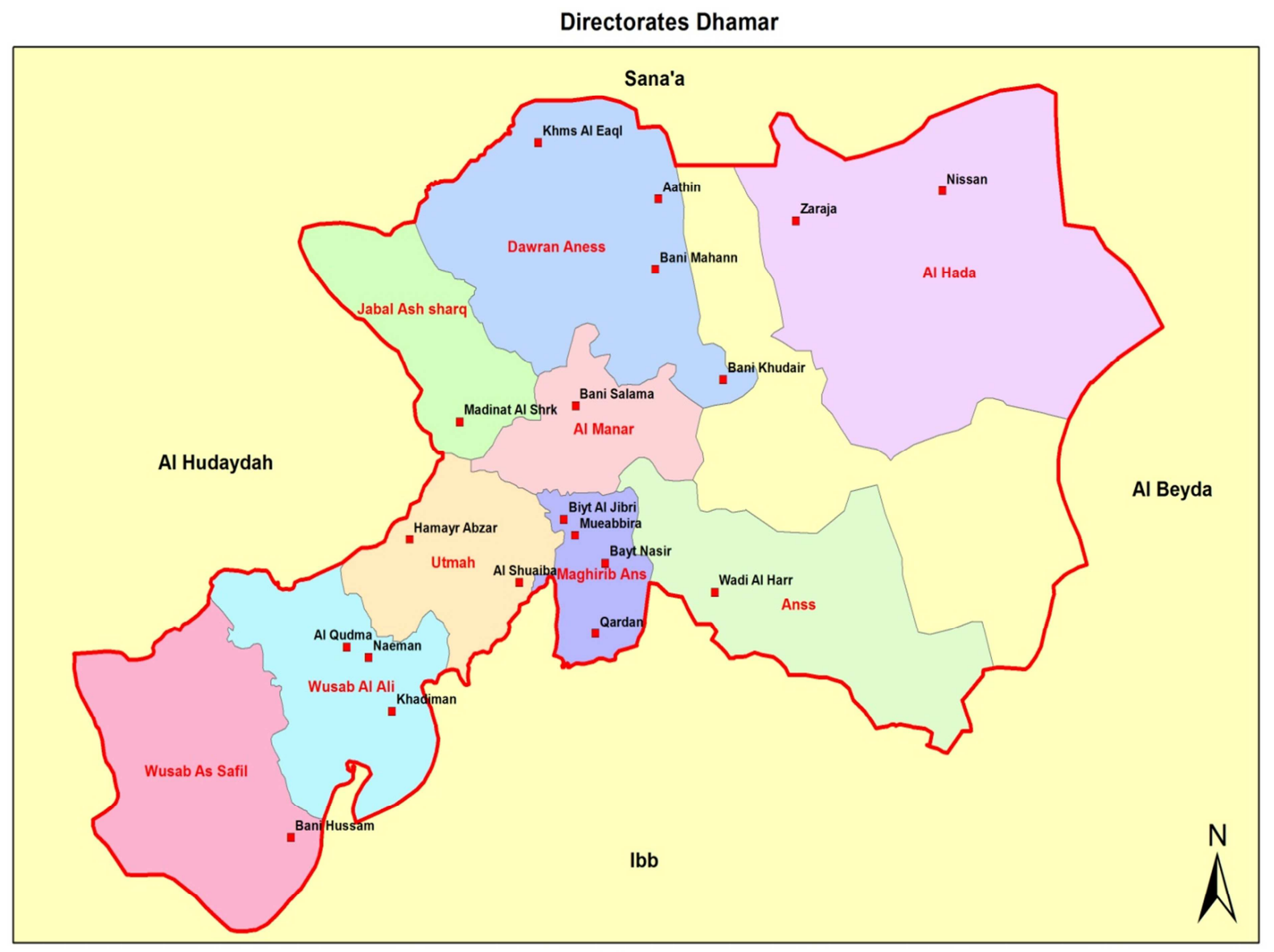

$1: 1, \cdots, \cdots$

Figure 1. Map of the affected districts with visceral leishmaniasis in Dhamar governorate. 


\section{Discussion}

$\mathrm{VL}$ is an endemic disease in Yemen. The most notable finding of this study is the diagnosis of all 57 cases of VL within Dhamar governorate, the central highland area with at least $3000 \mathrm{kms}$ above sea level. The majority of VL cases were identified in Anes district, A'ns, Wesab, Al hada and Automah. All of these districts represent the south west highlands of Dhamar and rising more than $2724 \mathrm{kms}$ above the sea level. The characteristics of these regions are villages scattered over mountains overlapping with some foothills and valleys. The people are mostly farmers with widespread of wild animals including domestic dogs. In addition, they are poor, low educated, having inadequate public health infrastructure, and poor sanitation. The people earn their living from sales of the agricultural products, small-scale business or depend on their daily manual labor. VL have developed for long time in the hot regions of Northern and Western plains where malarial infection is coexisted. The observed cases of VL in the central highlands suggest increasing spread of the disease to unusual sites as reported by several studies $[12,1]$. This could be explained at least in part by vectors adaptation to the changing climate observed recently.

The alternative explanation could be related to population displacement seen during the last five years due to political turmoil. Therefore, VL cases might have been exposed to L. donovani infection elsewhere. Population displacement during war has been described as a risk factor of increasing leishmaniasis cases in Iraq and Syria [13]. In Yemen, it is reported that the population movement from urban areas to villages, disrupted habitats of animal reservoirs and vectors due to current armed conflicts may be the most important risk factors for the increased transmission of the different forms of leishmaniasis [14]. In our setting, notification of VL cases is not demanding thus, the active foci cannot be followed and determined and the geographical distribution could not be mapped. Sharing of clinical features of VL with several feverish diseases, delay in the diagnosis and high lethality rate often before hospitalization further complicate the situation and account for underreporting the disease [15]. In the current study, it is found that the most frequent clinical presentations were fever and splenomegaly which affected all children. Abdominal distension was present in the majority of our patients reflecting the gross splenomegaly and / or hepatomegaly. These findings are consistent with other study [16]. It is reported that the hepatosplenomegaly could be the result of accumulation of mononuclear phagocyticytic cells causing hyperplasia of the reticuloendothelial cells, the principal involved system [17]. Hematological abnormalities in $\mathrm{VL}$ are common, chronic inflammation and dietary factors appear to be most common factors. Anemia was evident in all patients of this study with mean haemoglobin level of $6.51 \pm 2.82 \mathrm{~g} / \mathrm{dl}$. This finding is similar to other studies [18, 16]. The causes of anemia in patients with VL are multifactorial factors such as sequestration and destruction of red blood cells (RBC) in the enlarged spleen, immune hemolysis and alterations in RBC membrane permeability [19]. Neutropenia was less frequently found in our patients $(17.5 \%)$ and more than half of our patients developed thrombocytopenia. The presence of very low counts of neutrophils and platelets has been reported to increase the risk of death three and twelve folds respectively [20].

There are different strategies applied to control the vectors transmission including among others spraying houses with insecticide and treated bed nets [21]. It is reported that in countries with endemic VL such as Sudan, the incidence has been sharply reduced after a community distribution of insecticide treated nets [22]. However, the control of the disease relies on the people in the targeted area [23]. In some communities like ours, the implementation of the control program is less likely to success owing to the people low education, socio-economic factor and most importantly lack of individual awareness. Furthermore, the controlling of the animal reservoir hosts appears difficult in such agricultural areas where the density of animals including domestic dogs is predominant and favourable by settlements. The increasing prevalence of VL and urbanization of the disease observed worldwide [1] should alarm the physicians as well as the health care system to go one step forwards. Nationwide notification of all VL cases plus some form of control programs is required. The current study showed a response rate to sodium stibogluconate treatment as $94.8 \%$. This finding is similar to the data derived from Ethiopia that reported the initial cure rates of $95 \%$ [24]. The high cure rate observed in this study could be also attributed to aggressive adjunctive care provided for pediatric patients. The specific anti leishmania agents are only part of the treatment for VL patients. Supportive care including managing and preventing the complications of VL is very important [25]. All of patients in this study received blood products and dietary support. However, the sole dependence on chemotherapy is no more acceptable and the demand for the development of an efficient vaccine is needed [26].

Death was occurred in 3 cases (5.2\%) of pediatric patients in this study and seen among patients with age blew one year, prolonged illness prior to treatment, severe anemia and large spleen size. It is reported that the overall case-fatality rate of $\mathrm{VL}$ is around $10 \%[27]$.

\section{Conclusion}

This study confirmed the presence of VL cases in Dhamar governorate, most frequently affected children below four years of age with excellent response to chemotherapeutic drug. Existence of VL foci in the highest central highlands indicating that the disease tend to spread into other virgin parts of the country. Such a new distribution combined with lack of vital recording and reporting make the efforts to approximate the figure of true incidence difficult. Correction of the factors contributing to under reporting of $\mathrm{VL}$ and better surveillance system through collection of community- 
based data are urgently needed.

\section{References}

[1] Albuquerque PL, Silva Júnior GB, Freire CC, Oliveira SB, Almeida DM, Silva HF, et al. Urbanization of visceral leishmaniasis (Kala-azar) in Fortaleza, Ceará, Brazil. Pan Am J Public Health. 2009, 26 (4): 330-333.

[2] Olliaro PL, Guerin PJ, Gerstl S, Haaskjold AA, Rottingen JA, Sundar S. Treatment options for visceral leishmaniasis: a systematic review of clinical studies done in India, 1980-2004. Lancet Infect Dis. 2005 Dec; 5 (12): 763-74.

[3] World Health Organization. Leishmaniasis Disease Burden. Available from:http://www.who.int/leishmaniasis [Last cited on 2015 August 19].

[4] Holtez PJ, Molyneux DH, Sachs SE, Fenwick A, Kumerasan J, Sacks JD, et al. Control of neglected tropical diseases. $N$ Engl J Med. 2007; 357: 1018-27.

[5] Chappuis F, Sundar S, Hailu A. Ghalib H, Rijal S, Peeling RW et al. Visceral leishmaniasis:what are the needs for diagnosis, treatment and control?. Nature Review/Microbiology 2007; 5: 873-828.

[6] Rocha NA, Júnior GB, Oliveira MJ, Abreu KL, Franco LF, Silva MP, Garcia AV, Daher EF. Visceral leishmaniasis in children: a cohort of 120 patients in a metropolitan city of Brazil. The Turkish journal of pediatrics. 2011 Mar 1; 53 (2): 154.

[7] Pastorino C, Jacob CMA, Oselka GW \& Carneiro-Sampaio MS. Visceral leishmaniasis: clinical and laboratorial aspects. $J$ Pediatr 2002; 78: 120-127.

[8] Queiroz M J, Alves J G, Correia J B. Visceral leishmaniasis: clinical and epidemiological features of children in an endemic area. Journal de pediatria, 2004; 80 (2): 141-146.

[9] Hamid GA, Gobah GA. Clinical and hematological manifestations of visceral leishmaniasis in Yemeni children. Cough. 20091 (29): 45-3.

[10] Al-Selwi AA, Al Sherei AG, Al Magrami AS. Clinical and epidemiological features of visceral leishmaniasis Among children in Yemen: one referral hospital review. Sudan Medical Journal. 2016; 52: 7-15.

[11] Central Statistical Organization. Census 2004. Available at http://www.geohive.com/cntry/yemen.aspx (accessed 4 Jan 2017.

[12] Cavalcante LJ, Vale MR. Epidemiological aspects of visceral leishmaniasis (kala-azar) in Ceará in the period 2007 to 2011. Ver Bras Epidemiol. 2014; 17: 911-24.

[13] Salam, N, Al-Shaqha WM, and Arezki A. "Leishmaniasis in the Middle East: Incidence and Epidemiology." PLoS Negl $\begin{array}{lllll}\text { Trop Dis 2014; } 8 \text { (10): e3208. doi: } & \end{array}$ 10.1371/journal.pntd.0003208.

[14] El Sawaf BM, Kassem HA, Mogalli NM, El Hossary SS, Ramadan NF. Current knowledge of sand fly fauna (Diptera: Psychodidae) ofnorthwestern Yemen and how it relates to leishmaniasis transmission. Acta Tropica 2016; 162: 11-19.

[15] Gülez P, Gülez N, DevrimF, Erdoğan DB. Delay in Diagnosis in Children with Visceral leishmaniasis: A Single-Center Experience. J Pediatr Inf 2015; 9: 12-6.

[16] Haidar NA, Diab AB, El-Sheik AM. Visceral Leishmaniasis in children in the Yemen. Saudi Med J 2001; 22: 156-9.

[17] Pace D, Williams TN, Grochowska A Betts A, AttardMontalto S, Boffa MJ et al. Manifestations of paediatric Leishmania infantum infections in Malta. Travel medicine and infectious disease, 2011; 9 (1): 37-46.

[18] JamilL A, Zafer M, AL-Fifi S, AL-JARIE A, AL-SHRAIM M, SHABANA M et al. Clinical and Pathological Features of Visceral Leishmaniasis in Pediatric Patients, Aseer Province, Southwestern Saudi Arabia. Med J Cairo Univ 2012; 80 (2): 121-6.

[19] Varma, Neelam, and Shano Naseem. "Hematologic changes in visceral leishmaniasis/kala azar." Indian Journal of Hematology and Blood Transfusion 2010; 26(3): 78-82.

[20] Sampaio m. JAQ, Cavalcanti NV., Alves JGB., Filho MJCF. and Correia J. B.: Risk Factors for Death in Children with Visceral Leishmaniasis. PLoS Negl. Trop. Dis. 2010; 4 (11): e877.

[21] Daniel SO, Veronica MA, Soledad SM. Visceral leishmaniasis: Path that converge and divide. Salud Colectiva, Buenos Aires 2012; 8 (suppl 1): 549-563.

[22] Reithinger R, Dujardin JC, Louzir H, Pirmez C, Alexander B, et al.) Cutaneous leishmaniasis. Lancet Infect Dis 2007; 7: 581-596.

[23] Davies CR, Kaye P, Croft SL, Sundar S. Leishmaniasis: new approaches to disease control. BMJ 2003; 326: 377-382.

[24] Ritmeijer K, Dejenie A, Assefa Y, Hundie TB, Mesure J, Boots $\mathrm{G}$, et al. A comparison of miltefosine and sodium stibogluconate for treatment of visceral leishmaniasis in an Ethiopian population with high prevalence of HIV infection. Clin Infect Dis. 2006; 43: 357-64.

[25] Moore EM, Lockwood DN. Treatment of Visceral leishmaniasis. J Glob Infect Dis. 2010; 2 (2): 151-158.

[26] Bessat M, Okpanma AC, Shanat ES. Leishmaniasis: Epidemiology, Control and Future Perspectives with Special Emphasis on Egypt. J Trop Dis 2015; 2: 153.

[27] Collin S, Davidson R, Ritmeijer K, Keus K, Melaku Y, Kipngetich S, et al. Conflict and kala-azar: determinants of adverse outcomes of kala-azar among patients in southern Sudan. Clin Infect Dis 2004; 38: 612-619. 